\title{
In reply: Bilateral scalp blocks help reduce postoperative pain and opioid requirement, but the impact cannot be so huge
}

\author{
Andrea Rigamonti, MD • Kan Ma, MD • Marco M. Garavaglia, MD • \\ Gregory M. T. Hare, MD • C. David Mazer, MD
}

Received: 10 May 2020/Revised: 10 May 2020/Accepted: 10 May 2020/Published online: 20 May 2020

(c) Canadian Anesthesiologists' Society 2020

\section{To the Editor,}

We appreciate the letter of Drs Bhakta and Dash ${ }^{1}$ regarding our study of bilateral scalp blocks aimed at reducing postoperative pain and opioid requirements. ${ }^{2}$ As stated in our original manuscript, opioid use was protocolized-i.e., 1) fentanyl (1.5-3 $\left.\mu \mathrm{g} \cdot \mathrm{kg}^{-1} i v\right)$ and remifentanil $\left(1-1.5 \mu \mathrm{g} \cdot \mathrm{kg}^{-1} i v\right)$ to blunt the impact of endotracheal intubation; 2) remifentanil infusion (0.0-0.5 $\left.\mu \mathrm{g} \cdot \mathrm{kg}^{-1} \cdot \mathrm{min}^{-1} i v\right)$ to treat varying levels of intraoperative pain and to minimize volatile anesthetic requirement; and 3 ) intraoperative titration of hydromorphone $(0.4-1.2 \mathrm{mg}$

A. Rigamonti, MD $(\bowtie) \cdot$ K. Ma, MD · M. M. Garavaglia, MD Department of Anesthesia, St. Michael's Hospital, University of Toronto, Toronto, ON, Canada

e-mail: Andrea.Rigamonti@unityhealth.to

G. M. T. Hare, MD

Department of Anesthesia, St. Michael's Hospital, University of Toronto, Toronto, ON, Canada

St. Michael's Hospital Center of Excellence for Patient Blood Management, Toronto, ON, Canada

Keenan Research Centre for Biomedical Research, Li Ka Shing Knowledge Institute, Toronto, ON, Canada

Department of Physiology, University of Toronto, Toronto, ON, Canada

C. D. Mazer, MD

Department of Anesthesia, St. Michael's Hospital, University of Toronto, Toronto, ON, Canada

Keenan Research Centre for Biomedical Research, Li Ka Shing Knowledge Institute, Toronto, ON, Canada

Department of Physiology, University of Toronto, Toronto, ON, Canada $i v)$ to initiate treatment of postoperative craniotomy pain. Although not reported in the original manuscript, there was no difference in the mean (standard deviation) intraoperative fentanyl dose [177 (63) $\mu \mathrm{g} v s 152$ (87) $\mu \mathrm{g}$; students $t$ test, $P=0.13$ ] and a small difference in hydromorphone use $[1.1(0.4) \mathrm{mg}$ in the treatment group $v s$ $0.9(0.5) \mathrm{mg}$ in the control group; $P=0.03$ ]. Although this difference was statistically significant, we do not believe that $0.2 \mathrm{mg}$ of hydromorphone is a clinically significant difference. We intentionally allowed a relatively broad dosage range of remifentanil (from $0.0-0.5 \mu \mathrm{g} \cdot \mathrm{kg}^{-1} \cdot \mathrm{min}^{-1}$ $i v)$ to permit the attending anesthesiologist to address the different analgesia requirements throughout the entire surgery. It has been well known since the early $1900 \mathrm{~s}^{3}$ that craniotomy has a broad range of pain and analgesia/ anesthesia requirements at different phases of the surgery. A remifentanil infusion has an optimal pharmacokinetic profile to address this. Nevertheless, we did not record the total dose of intraoperative remifentanil as the drug has a very short half-life that substantially minimizes, though does not completely eliminate, any potential confounding of clinical outcomes.

Our report also states that anesthesia was maintained with sevoflurane (minimum alveolar concentration, 0.81.2), which is well within the accepted range to provide balanced general anesthesia with concurrent use of opioids. ${ }^{4}$ Though no optimal monitor for intraoperative awareness is yet available clinically, we provided generally accepted levels of sevoflurane anesthesia to prevent awareness. The study referenced by the authors to support their comment refers to a completely different scenario (cardiac surgery) and does not apply to our population. Our patients only received rocuronium to facilitate endotracheal intubation. A patient who is anesthetized but not paralyzed can move in response to a 
painful stimulus if the analgesia/anesthesia is inadequate, thus serving as a warning sign that the anesthetic depth and/or analgesia are inadequate. Moreover, no subjects in our study reported intraoperative awareness.

We placed a scalp block at the end of the surgical procedure to extend the postoperative analgesic effect of the block. In our institution, this is easily done with the head frame still in place. We are surprised by the comment by Bhakta and Dash ${ }^{1}$ as access to the occipital nerves is actually easier with the head still positioned in the frame as opposed to having the head resting on the operating table. Epinephrine was added to the sham arm to control for any effect of this drug in the treatment group.

The authors raise an interesting point about the pain visual analogue scale outcome. Our findings support the authors' suggestion that the scalp block has a short-term effect within the first $12 \mathrm{hr}$. This secondary outcome has informed our use of scalp block for awake craniotomy procedures where we find a circumferential scalp block to be an important aspect of the anesthetic management for patients undergoing awake craniotomy. ${ }^{5,6}$ Notably, we did not find any significant differences in the long-term secondary outcomes at postoperative day 30 or 60 , and see no reason to believe that the effect at 90 days would be any different.

Lastly, our report did not suggest that we should change existing opioid practices based on our results.

Disclosures None.
Funding statement None.

Editorial responsibility This submission was handled by Dr. Hilary P. Grocott, Editor-in-Chief, Canadian Journal of Anesthesia.

\section{References}

1. Bhakta P, Dash H. Bilateral scalp blocks help reduce postoperative pain and opioid requirement, but the impact cannot be so huge. Can J Anesth 2020; DOI:https://doi.org/10.1007/s12630-02001711-7.

2. Rigamonti A, Garavaglia MM, Ma K, et al. Effect of bilateral scalp nerve blocks on postoperative pain and discharge times in patients undergoing supratentorial craniotomy and general anesthesia: a randomized-controlled trial. Can J Anesth 2020; 67: 452-61.

3. Horsley $V$. Address in surgery delivered at The Seventy-Fourth Annual Meeting Of The British Medical Association, on the technique of operations on the central nervous system. Br Med J 1906; 2382: 411-23.

4. Nickalls $R W$, Mapleson $W W$. Age-related iso-MAC charts for isoflurane, sevoflurane and desflurane in man. Br J Anaesth 2003; 91: 170-4.

5. Garavaglia MM, Das $S$, Cusimano $M D$, et al. Anesthetic approach to high-risk patients and prolonged awake craniotomy using dexmedetomidine and scalp block. J Neurosurg Anesthesiol 2014; 26: 226-33.

6. McAuliffe N, Nicholson S, Rigamonti A, et al. Awake craniotomy using dexmedetomidine and scalp blocks: a retrospective cohort study. Can J Anesth 2018; 65: 1129-37.

Publisher's Note Springer Nature remains neutral with regard to jurisdictional claims in published maps and institutional affiliations. 